\title{
DAMPAK IKLAN TERHADAP KELAS SOSIAL DALAM MASYARAKAT
}

\author{
Aryo Bimo \\ Jurusan Desain Komunikasi Visual, Fakultas Komunikasi dan Multimedia Universitas Bina Nusantara \\ Jl. K.H. Syahdan No. 9, Palmerah, Jakarta Barat 11480 \\ obeems@binus.ac.id
}

\begin{abstract}
Article described the growth of advertisement in Indonesia that is quite rapid and its' impacts on the social classes. Advertisement's rapid growth was evidenced by the relatively high increase in expenditure, i.e. up to 13 percent. If calculated to October 2009, the total advertising expenditure Indonesia had reached 40 trillion IDR. Advertising was often considered as a cause of increased consumptive lifestyles in society. In addition, advertising was considered to be responsible in creating social classes in society. Therefore, article would like to discuss how these ads can distinguish groups of people with communication conducted in an advertisement.
\end{abstract}

Keywords: advertisement, social class, society

\begin{abstract}
ABSTRAK
Artikel menggambarkan perkembangan periklanan di Indonesia yang sangat cepat dan dampaknya pada kelas sosial di masyarakat. Peningkatan periklanan di Indonesia dibuktikan dengan peningkatan belanja iklan yang terbilang tinggi, yakni hingga 13 persen. Jika dikalkulasikan hingga Oktober 2009, jumlah belanja iklan Indonesia sudah mencapai Rp 40 triliun. Iklan sering dianggap sebagai penyebab meningkatnya pola hidup konsumtif di masyarakat. Selain itu, iklan pun dianggap bertanggung jawab dalam menciptakan kelas sosial di masyarakat. Oleh karena itu, artikel membahas bagaimana iklan tersebut bisa membeda-bedakan kelompok masyarakat dengan komunikasi yang telah dilakukan dalam sebuah iklan.
\end{abstract}

Kata kunci: iklan, kelas sosial, masyarakat 


\section{PENDAHULUAN}

Periklanan di Indonesia memiliki perjalanan yang cukup panjang. Sejarah periklanan sudah dimulai sejak jaman VOC, khususnya pada saat kepemimpinan Jan Pieterszoon Coen. Namun periklanan modern mulai dirintis pada akhir 1960an, pada waktu Indonesia sudah memiliki stasiun radio dan TV nasional. Di akhir tahun 1970-an periklanan modern Indonesia mulai berkembang seiring dengan perkembangan media dan teknologi. Perkembangan dimulai dari perintis periklanan modern di Indonesia, yaitu Nuradi pada tahun 1968 yang mendirikan biro iklan bernama Inter Vista., kemudian diikuti dengan biro iklan yang lain seperti Matari, Lintas, Indo-Ad, dll.

Pada era Orde Baru tahun 1980an iklan sempat dilarang sama sekali penayangannya di TVRI. Sampai pada tahun 1989 iklan TV kembali diijinkan penayangannya setelah kemunculan siaran TV swasta yang pertama, yaitu RCTI. Pada tahun 1990-2000-an iklan di Indonesia kembali bergairah dan semakin kuat. Iklan mengalami "booming”. Hal ini dilihat dengan semakin banyaknya biro iklan baik multinasional (asing) maupun lokal.

Periklanan di Indonesia mengalami perkembangan yang cukup signifikan, terbukti dari hasil survei AC Nielsen, yaitu peningkatan belanja iklan yang terbilang tinggi, yakni mencapai 16 persen. Jika dikalkulasikan hingga Oktober 2009, jumlah belanja iklan Indonesia sudah mencapai Rp 48.5 triliun. (Solo Pos, 2010)

Perkembangan iklan di Indonesia selain berdampak pada perekonomian juga memiliki peran penting dalam membentuk gaya dan pola hidup masyarakat Indonesia, khususnya yang tinggal di perkotaan. Sadar atau tidak perilaku kita sekarang ini sedikit banyak dipengaruhi oleh iklan. Setiap hari kita dibombardir oleh ribuan iklan, baik itu iklan media cetak, iklan TV, dan radio. Belum lagi iklan yang dipasang di sepanjang jalan dan di mana saja kita bisa bersinggungan dengan iklan tersebut.

Sangat menarik melihat bagaimana sebuah iklan bisa menghipnotis audiensnya untuk mempengaruhi dan kemudian membeli produk yang ditawarkan. Dengan berbagai strategi komunikasi kreatif dan gaya persuasi yang sedemikian rupa, sebuah iklan mampu "mendikte" masyarakat. Bagaimana akhirnya masyarakat bisa dikelompokkan dalam berbagai kelompok pasar, yaitu masingmasing kelompok tersebut memiliki karakteristik yang unik dan berbeda satu sama lain karena pengaruh iklan.

\section{METODE}

Penelitian disusun menggunakan pendekatan studi literatur untuk mendapatkan data pendukung serta mencari kerangka teori guna menguatkan hasil penelitian. Kemudian setelah data diperoleh, dilakukan analisis data reflektif. Analisis Reflektif adalah metode analisis data yang berpedoman pada cara berfikir reflektif. Pada dasarnya, metode ini adalah kombinasi yang kuat antara berpikir deduktif dan induktif atau dengan mendialogkan data teoritik dan data empirik secara bolak balik kritis.

Dengan metode Analisis Reflektif, akan dicari makna yang terkandung dari hasil pengumpulan data yang telah dilakukan, untuk dibandingkan antara literatur yang ada dengan keadaan ataupun fenomena yang tertangkap, sehingga dapat diperoleh simpulan data yang rasional dan ilmiah. 


\section{PEMBAHASAN}

\section{Teori yang dipakai}

Iklan adalah salah satu proses untuk mendoktrin sebuah ideologi ke dalam benak konsumen, sehingga konsumen merasa bahwa mereka adalah bagian dari iklan tersebut (Williamson, 1978). Oleh karena itu, mereka akan membeli produk atau mencoba jasa yang ditawarkan oleh sebuah iklan karena audiens merasa bahwa mereka memang bagian dari kelompok yang dituju oleh iklan tersebut.

Proses ini merupakan pengelabuan atas kenyataan kelas sosial tempat kita sesungguhnya berada. Proses jual beli, yang sebenarnya adalah merupakan proses pendistribusian produk ke masyarakat, seolah-olah menjadi proses peningkatan kelas. Kepemilikan atas produk menutupi kelas sosial yang sebenarnya. Lapisan penutup inilah yang merupakan ideologi. Ideologi adalah makna yang dijadikan kebutuhan oleh pelbagai kondisi masyarakat sembari turut serta melanggengkan kondisi. (Williamson, 1978: 13).

Iklan sering melakukan pendekatan dengan cara menghubungkan produk tertentu dengan satu set kualitas atau keuntungan dalam benak konsumen. Penghubungan ini seringkali dicapai melalui penanaman kualitas produk ke dalam benak konsumen, Kemudian, kualitas tersebut akan berpindah dari produk kepada konsumen seketika setelah produk tersebut dibeli. Pada dasarnya, hal ini berarti bahwa kita mendefinisikan diri kita berdasarkan apa yang kita miliki - dan iklan adalah jalur tempat kita mendapatkan identitas tersebut. (Williamson, 1978: 13)

"Kami membedakan diri dari orang lain dengan apa yang kita beli (Williamson, 1978: 46)”. Diferensiasi tidak hanya sekedar dalam hal pencitraan dan memisahkan produk satu dgn produk lainnya, diferensiasi juga terkait dengan identitas kita. Williamson berpendapat bahwa adalah bagaimana sebuah pencitraan bekerja. "Produk dapat "menghasilkan" atau "membeli” perasaan. Namun tingkat yang lebih halus di mana iklan itu bekerja adalah faktor 'alreadyness', di mana 'totemisme' menjadi bagian dari ideologi: Anda tidak hanya membeli produk dalam rangka untuk menjadi bagian dari kelompok yang diwakilinya akan tetapi Anda akan merasa bahwa Anda seperti sudah termasuk dalam kelompok tersebut dan karena itu Anda akan membelinya "(Williamson, 1978: 47). Intinya adalah ideologi memberi kita jaminan bahwa kita adalah siapa kita, kita adalah individu yang terpisah dengan identitas kita sendiri dan kami akan membeli produk yang berbicara dengan identitas kita sendiri. Seperti Williamson katakana bahwa, "mitos" tersebut di atas sangat penting untuk memastikan bahwa kita bertindak sesuai dengan keyakinan kita tentang siapa kita. (Williamson, 1978: 46-47)

\section{Pembahasan iklan}

Untuk membuktikan bahwa teori Williamson penulis akan membahas beberapa iklan media cetak dan televisi sebagai berikut: 


\section{Iklan Lux}

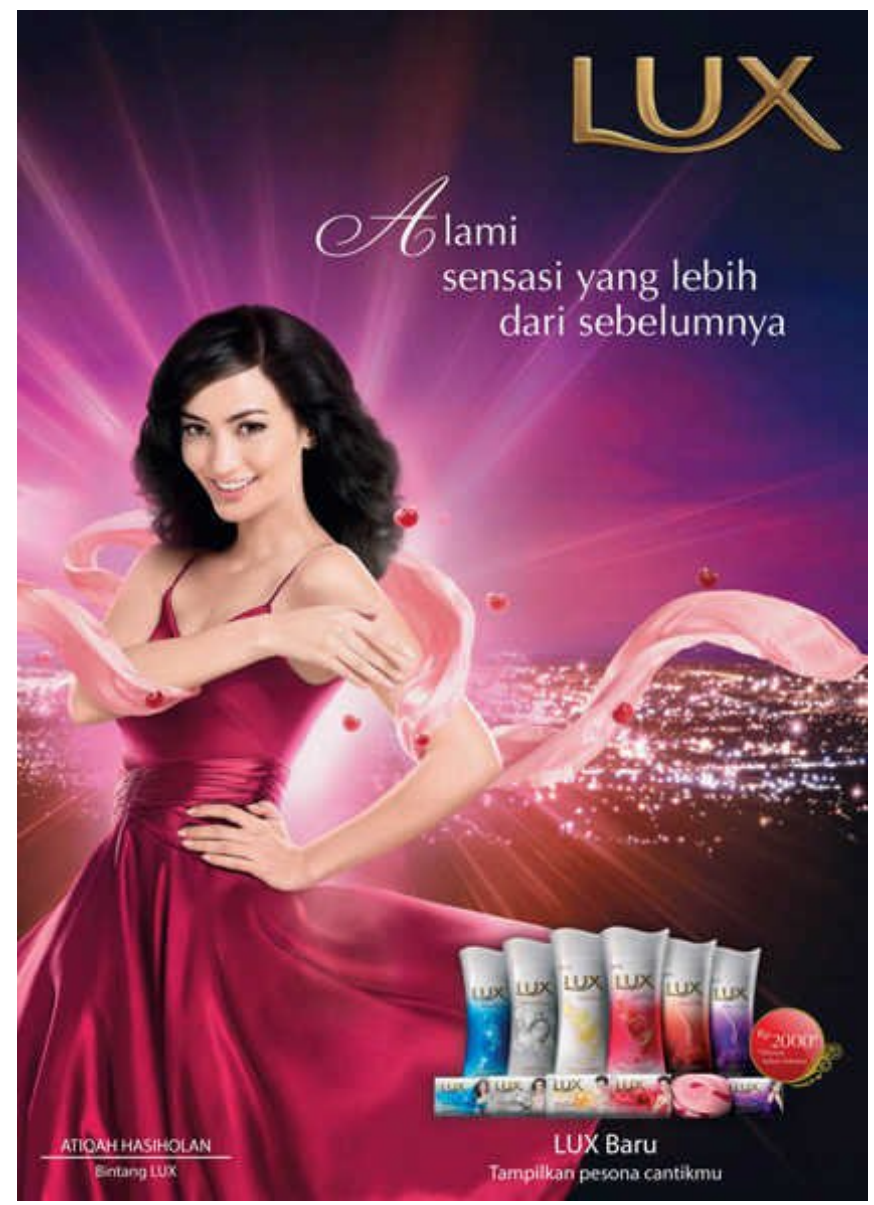

Gambar 1 Iklan Lus versi Atiqah Hasiholan Sumber: mazEka (2010)

Produk: Lux, sabun mandi cair dan batang

Biro iklan : John Walter Thompson, Jakarta (JWT Indonesia)

Tahun : 2010

Model iklan : Atiqah Hasiholan

Iklan di Gambar 1 mengomunikasikan bahwa kini sabun Lux tersedia dalam varian dan kemasan baru. Seperti diketahui, sabun Lux merupakan merek sebuah produk sabun mandi yang sudah cukup lama berada di Indonesia. Citra sabun Lux sudah terbangun sedemikian rupa dengan dukungan seluruh materi komunikasi, salah satunya iklan. Sesuai dengan posisi merek sabun Lux yaitu sabunnya para bintang. Hal ini yang membedakan Lux dengan para kompetitor di kategori sabun mandi.

Lux selalu menggunakan model iklan perempuan cantik yang biasanya merupakan selebriti atau aktris terkenal di Indonesia. Dengan menggunakan aktris atau selebriti wanita terkenal memang memperkuat citra sabun Lux sebagai sabunnya para bintang. Konsumen dibuai dengan janji tampil bak bintang jika mereka memakai sabun Lux. Di sini pencitraan bekerja untuk sedemikian rupa membujuk para target audiens (konsumen) mereka. Ada suatu persepsi bahwa jika Anda (para wanita) memakai sabun Lux seakan-akan Anda naik "peringkat" dari yang tadinya wanita biasa menjadi wanita yang "tidak biasa” lagi alias bak bintang terkenal. 
Pencitraan diperkuat dengan tampilan visual. Si model berdandan dan berpenampilan glamor seperti bintang terkenal, didukung dengan arahan fotografi dan pencahayaan yang artistik. Citra sabun Lux sendiri sudah menjadi sebuah "ideologi” atau "identitas" yang menempel kuat di benak konsumen mereka, sehingga para konsumen sabun Lux sudah merasa bahwa mereka adalah bagian dari "ideologi" tersebut. Identitas konsumen sabun Lux adalah mereka yang berpenampilan seperti layaknya seorang artis atau bintang terkenal.

\section{Iklan L’Oreal}

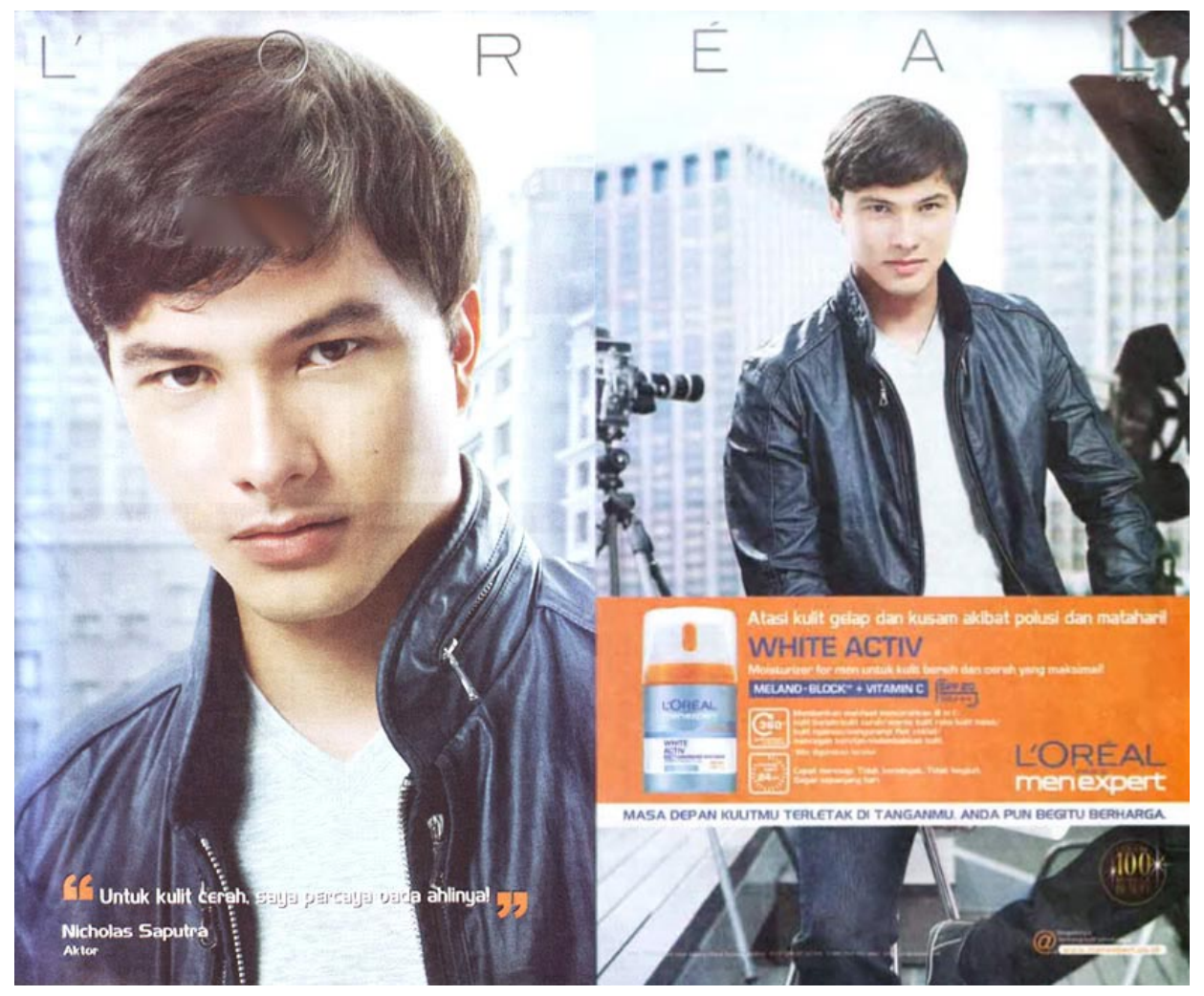

Gambar 2 Iklan L’Oreal for men

Produk : L’Oreal White Activ for men

\section{Biro iklan : McCann World Group, Jakarta \\ Tahun : 2010 \\ Model iklan : Nicolas Saputra}

Kita lebih mengenal L’Oreal sebagai merek produk kecantikan yang diperuntukkan khusus bagi wanita. Namun, dengan perkembangan zaman ternyata yang membutuhkan perawatan diri, khususnya wajah, bukan lagi dominasi kaum wanita. Kaum pria pun sekarang sudah sangat sadar akan pentingnya perawatan wajah demi menjaga penampilan mereka, oleh karena itu L’Oreal mengeluarkan produk yang diciptakan khusus pria.

Penggunaan artis, selebriti, atau tokoh terkenal memang biasa dilakukan oleh pengiklan untuk menumbuhkan citra positif bagi konsumen. Penggunaan Nicolas Saputra dalam iklan ini dianggap cukup merepresentasikan kaum pria modern masa kini yang memang sangat menjaga penampilan. 
Disela-sela kesibukan sebagai artis Nicolas tetap tidak lupa untuk selalu menjaga perwatan wajahnya agar tetap tampil menawan di setiap aktivitasnya sebagai model iklan dan aktor film layar lebar.

Penggunaan artis atau selebriti terkenal juga dianggap mewakili aspirasi para konsumen. Konsumen seakan-akan naik satu peringkat dari posisi mereka sebelumnya, bahkan konsumen yang tadinya hanya bukan siapa-siapa menjadi "sesuatu” yang tidak biasa lagi.

\section{Iklan Gudang Garam}

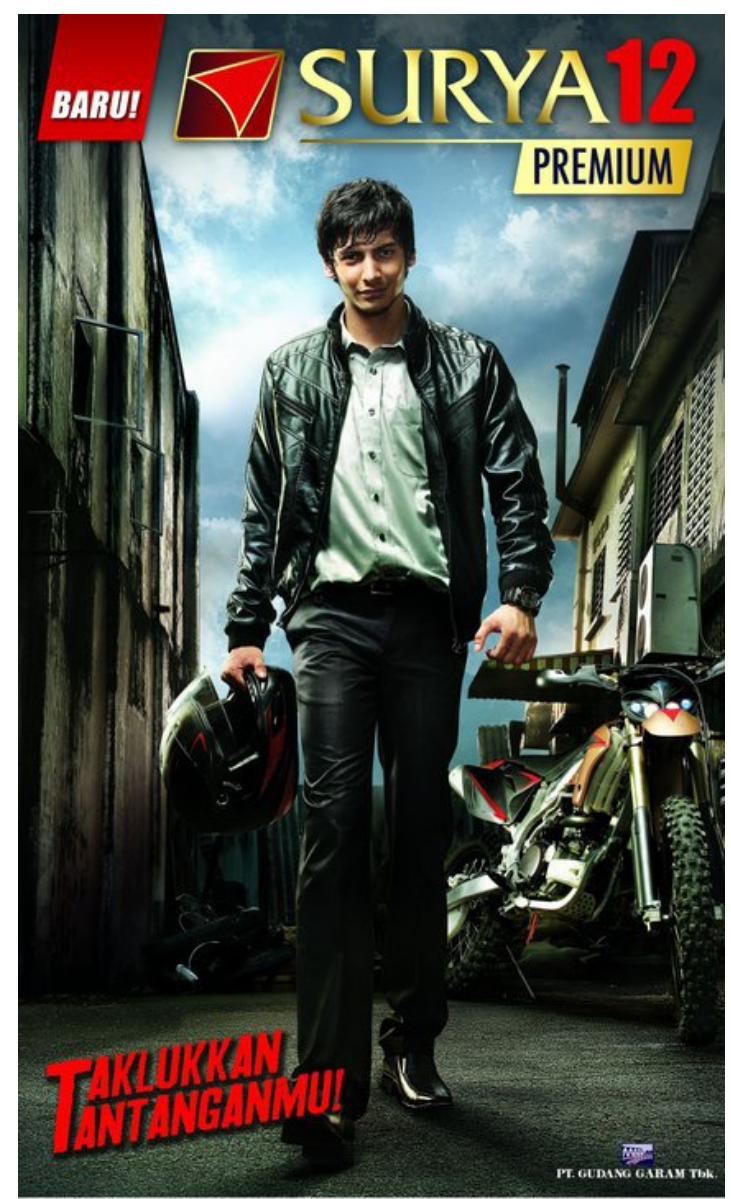

Gambar 3. Iklan Gudang Garam Surya 12

Produk: Surya 12 Premium

Versi : Tertukar tas laptop

Biro iklan : McCann World Group, Jakarta

Tahun : 2010

Gudang Garam merupakan produsen rokok filter terbesar setelah Djarum dan grup Sampoerna. Seperti kebanyakan iklan rokok, mereka tidak boleh sama sekali memperlihatkan kegiatan merokok, mereka lebih bermain dari pencitraan maupun gaya hidup. Gudang Garam Surya 12 Premium ini mencitrakan bahwa produk mereka ditujukan bagi para pria muda yang berkelas, memiliki keberanian,dan selalu sanggup menerima tantangan. Sangat jelas terlihat dari gaya berpakaian mau pun penampilan si model iklan dalam iklan cetak di Gambar 3. Sang Model berperawakan sedang, namun memiliki postur tegap. Memiliki wajah yang cukup tampan walaupun berpenampilan agak "slengekan”, namun tetap terkesan dandy dan berpenampilan eksekutif muda. 
Iklan cetak ini adalah bentuk pengulangan iklan TV, yaitu dikisahkan Si Pemuda itu bersama rekan wanitanya hendak rapat dengan klien mereka di sebuah gedung megah. Di meja resepsionis ternyata tas laptop yang dibawa Si Pemuda tadi tertukar dengan tas laptop orang lain, padahal sebentar lagi mereka sudah harus menghadap klien. Kemudian, dia langsung mencari akal untuk mendapatkan tas laptop yang tertukar tadi dengan adegan aksi yang sangat menegangkan. Akhir cerita sudah bisa ditebak bahwa Si Pemuda akhirnya bisa mendapatkan tasnya dan hadir di rapat bahkan lebih cepat daripada Si Rekan Wanita. Untuk lebih jelasnya bisa dilihat pada Gambar 4 berikut.
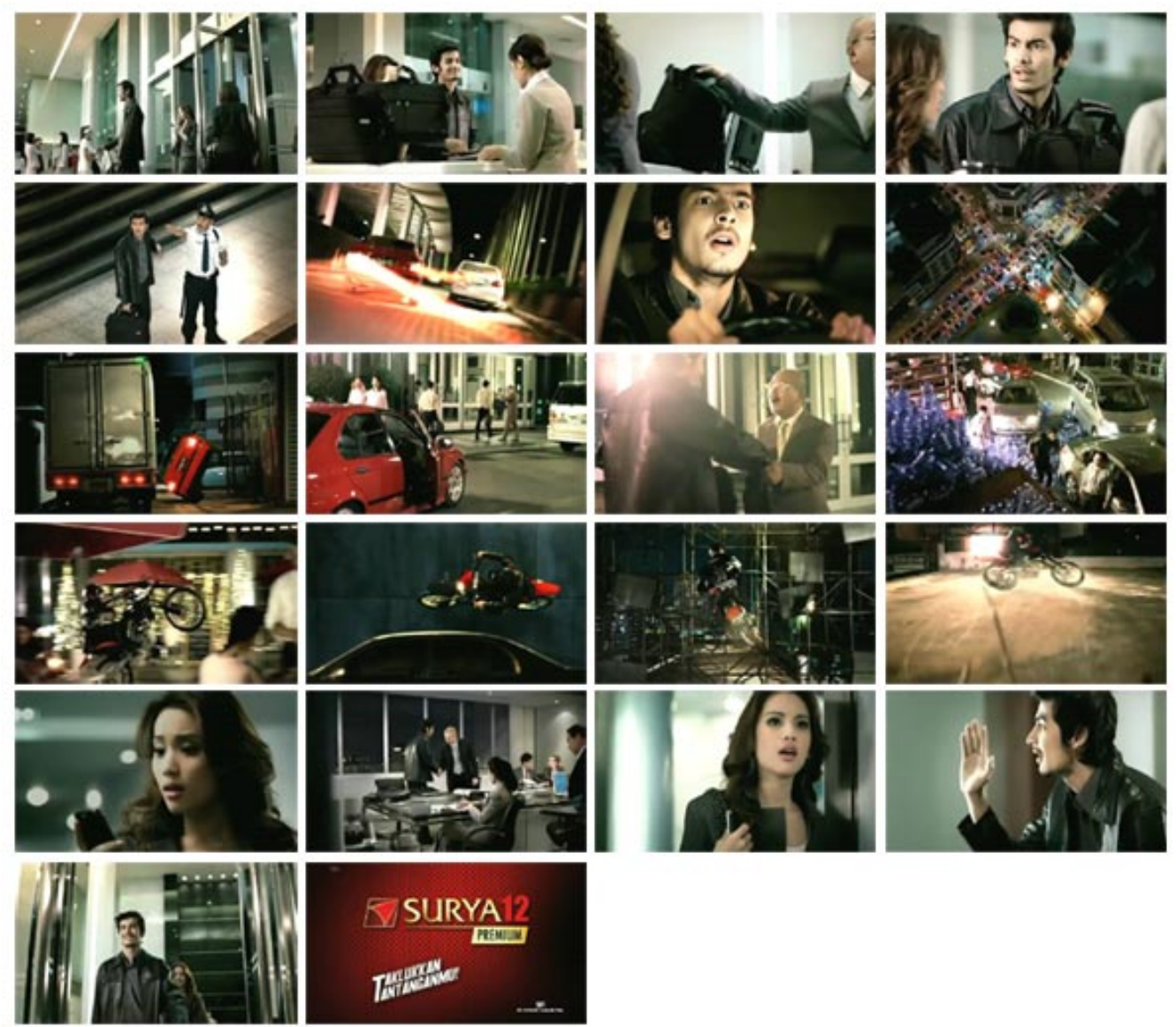

Gambar 4 Iklan TV Gudang Garam Surya 12

Komunikasi dengan gaya pencitraan seperti ini sering digunakan untuk produk rokok. Karena mereka tidak bisa memperlihatkan pemakaian produk sama sekali sesuai dengan peraturan undangundang periklanan yang dikeluarkan oleh P3I (Persatuan Perusahaan Periklanan Indonesia), maka iklan rokok herap didentikkan dengan Pria macho, pemberani atau jantan, dan keberhasilan suatu pencapaian atau kesuksesan (self esteem), sebagai ganjaran atau reward atas sebuah pencapaian.

Gudang Garam sebenarnya memiliki gaya pencitraan dengan menggabungkan kedua poin tersebut. Kesan jantan dan pemberani digambarkan dengan kehebatannya dalam pencarian tas laptop tadi dengan melakukan aksi yang berbahaya. Sementara, kesuksesan digambarkan dengan keberhasilan mendapatkan tas laptop dan dipertegas dengan tagline yang berbunyi "Taklukan Tantanganmu!”

Iklan ini memperlihatkan bagaimana Gudang Garam menanamkan kualitas produk, yang dicitrakan dengan pria pemberani tadi, ke dalam benak konsumen. Iklan tersebut juga mempengaruhi konsumen sedemikian rupa sehingga mereka timbul persepsi bahwa rokok Surya 12 Premium ini 
memang ditujukan untuk pria pemberani, suka dengan tantangan dan adrenalin, namun juga sukses dalam pencapaian hidup.

\section{Iklan M-150}

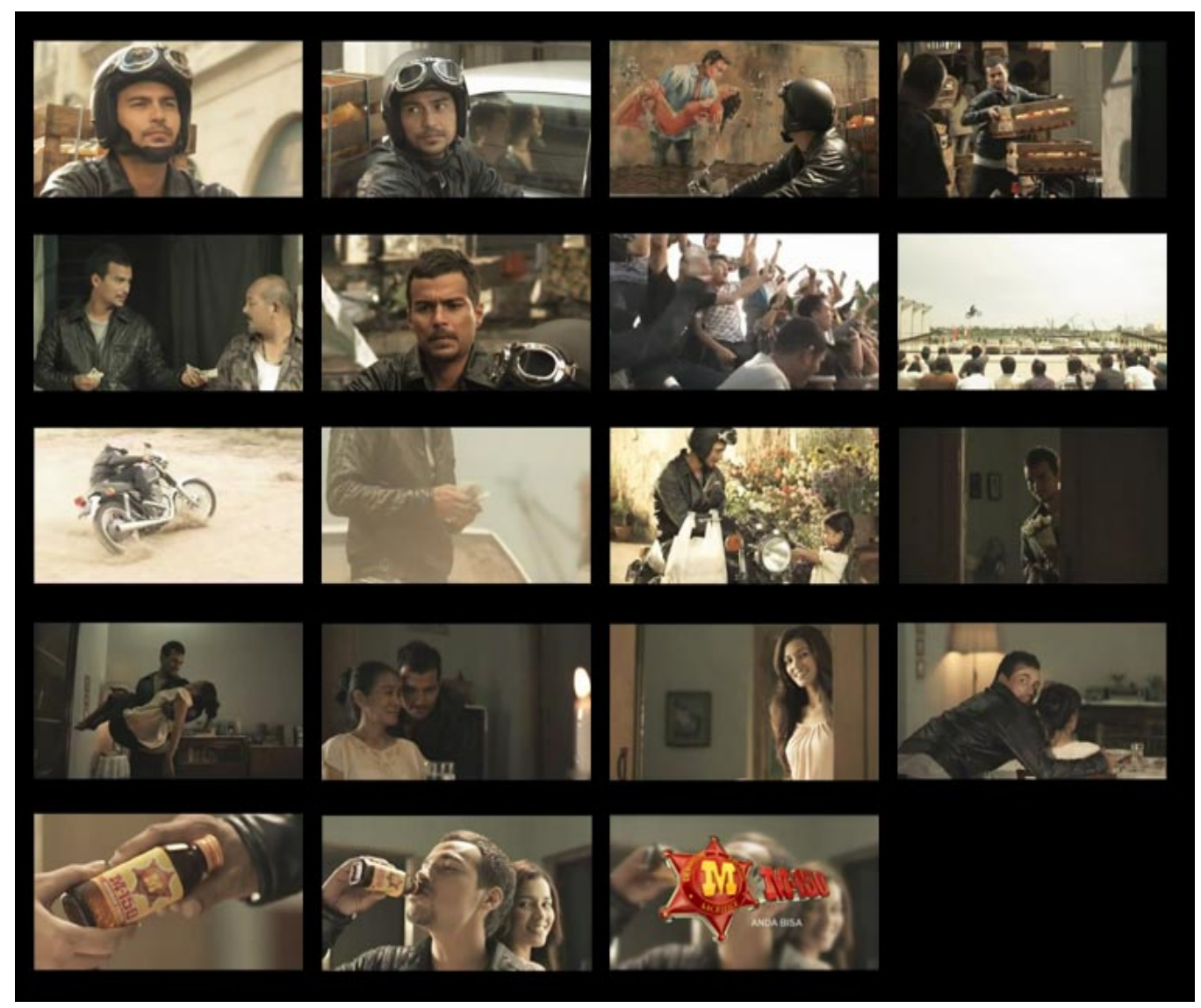

Gambar 4. Iklan TV M-150

\section{Produk: Minuman Energi \\ Versi : "Hero" \\ Biro iklan : Lowe Indonesia \\ Tahun : 2010}

M-150 merupakan minuman yang membangkitkan energi dan vitalitas pria. Sebelumnya, citra M-150 selalu dicitrakan sebagai pria tangguh dan aktif yang selalu menjadi pahlawan bagi orang yang dia sayangi (kekasih). Hal ini ditunjukkan dengan gaya yang berlebihan (exaggeration).

Pada komunikasi iklan TV di Gambar 4, M-150 ingin mengubah citra dari sisi pahlawan menjadi sedikit melodrama, yaitu dengan menggunakan pendekatan emosional. Dilihat dari dandanan, gaya berpakaian, pekerjaan, dan seting cerita digambarkan Si Pria berasal dari golongan ekonomi menengah ke bawah walau pun perawakan dan wajahnya tetap good looking. Iklan ini menceritakan seorang kurir dengan sepeda motornya yang bekerja sebagai pengantar barang. Dia berjuang agar bisa membahagiakan ibunya yang sedang sakit. Diceritakan bahwa dia sedang mengantar barang ke sebuah toko kelontong, kemudian untuk mendapatkan uang tambahan dia mengikuti atraksi adu nyali melompati beberapa mobil. Didukung dengan background musik "Hero" nya Mariah Carey membuat iklan TV M-150 ini semakin menyentuh. 
Dengan iklan ini M-150 ingin mengomunikasikan bahwa siapa pun bisa menjadi pahlawan bagi keluarga, walaupun dia hanya seorang kurir pengantar barang. Sisi pahlawan diangkat dengan gaya yang lebih menyentuh dan sangat emosional. Dari sisi cerita dan gaya penampilan Si Pria bisa dilihat bahwa M-150 menyasar konsumen dari kelas sosial ekonomi menengah ke bawah. Namun jika dilihat dari penampilan Si Pria, walau terlihat lusuh tetap ditampilkan memiliki wajah yang cukup tampan (good looking). Ini untuk menunjukkan unsur aspirasional bagi konsumen bahwa jangan terlalu harafiah dalam menunjukkan keseharian mereka, yaitu bahwa seorang kurir pengantar barang pasti berpenampilan lusuh, motornya jadul, dan berwajah mas-mas.

Dengan iklan TV ini M-150 juga menunjukkan bahwa kualitas produk mereka yang sejatinya memang minuman energi pembangkit vitalitas diterjemahkan lebih dari sisi emosional dari pada sisi kejantanan seperti yang telah mereka lakukan pada komunikasi sebelumnya. Mereka memperlihatkan sisi kepahlawanan Si Pria tersebut lebih dari sisi manusia, yaitu dia berjuang dan selalu berusaha keras demi untuk membahagiakan keluarga (terutama ibunya).

\section{PENUTUP}

Beberapa bahasan memperlihatkan pentingnya peran pencitraan sebuah merek dalam semua bentuk komunikasi, bagaimana proses menancapkan "ideologi” atau sebuah persepsi ke dalam benak konsumen, sehingga konsumen akan dipengaruhi sedemikian rupa sehingga mereka akan merasa bahwa produk yang ditawarkan sebuah merek memang mereka butuhkan. Dengan demikian, secara tidak sadar konsumen sudah menganggap bahwa mereka adalah bagian dari target yang disasar oleh iklan tersebut. Teori Judith Williamson yang mengatakan bahwa pencitraan dan ideologi itu memang terbukti dipakai dalam berbagai pendekatan komunikasi pada iklan di Indonesia. Pengaruh iklan telah mengelompokkan dan mengaspirasi konsumen sedemikian rupa sehingga mereka merasa bahwa mereka memang bagian dari kelompok tersebut dan merasa kelas sosial mereka akan setingkat lebih tinggi dari sebelumnya ketika memakai produk tersebut. Pencitraan yang dilakukan oleh si pengiklan akhirnya lebih dirasakan sebagai perwakilan dari citra konsumen itu sendiri dengan mereka memakai, membeli, atau mengonsumsi produk yang ditawarkan oleh si pengiklan. Dengan demikian, tanpa sadar sebenarnya sedikit banyak peri laku, gaya hidup, dan strata sosial kita ditentukan atau dipengaruhi oleh iklan.

\section{DAFTAR PUSTAKA}

Diunduh dari http://www.solopos.com/2010/ekonomi-bisnis/nielsen-belanja-iklan-di-indonesia-rp485-triliun-tahun-2009-12326, diakses 21 Januari 2011)

MazEka (2010), Print Ad Atiqah Hasiholan by LUXfanatic, Diunduh dari http://luxfanatic.blogspot.com/2010/11/new-lux-star-atiqah-hasiholan.html, diakses 22 Januari 2011)

Solo Pos (2010), Nielsen: Belanja iklan di Indonesia Rp 48,5 triliun tahun 2009, (Online)

Williamson, J. (1978). Decoding Advertisements: Ideology and Meaning in Advertising, London: Marion Boyars Publisher. 